\title{
Knowledge Creation and Transfer: Role of Learning Organization
}

\author{
Farhad Alipour (Corresponding author) \\ Department of Professional and Continuing Education \\ Faculty of Educational Studies, University Putra Malaysia 43400 Serdang, Malaysia \\ Tel: +60-132687691Ｅ-mail: alipoor_f@yahoo.com \\ Khairuddin Idris \\ Department of Professional and Continuing Education \\ Faculty of Educational Studies, University Putra Malaysia 43400 Serdang, Malaysia \\ E-mail: kidin@putra.upm.edu.my \\ Roohangiz Karimi \\ Department of Professional and Continuing Education \\ Faculty of Educational Studies, University Putra Malaysia 43400 Serdang, Malaysia \\ E-mail: roohangizkarimi@yahoo.com
}

Received: April 25, 2011

Accepted: July 27, 2011

doi:10.5430/ijba.v2n3p61

\begin{abstract}
This paper describes how knowledge is created and transferred in organizations. It also discuses conditions required in promoting knowledge creation, the techniques used to capture knowledge in organizations, the nature of learning organizations and how it can influence knowledge creation and transfer. By utilizing previous studies, the researchers present an integrated view of how learning organization affects knowledge creation and transfer.
\end{abstract}

Keywords: Knowledge Creation, Knowledge Sharing, Knowledge Transfer, Knowledge Conversion, Learning Organization

\section{Introduction and problem statement}

Fostering competitive advantage and optimizing organizational performance in the current complex and dynamic environment requires an organization's capability to create and transfer new knowledge and practice. Based on Ichij \& Nonaka (2007) the success of a company in the twenty-first century will be determined by the extent to which an organization's members can develop their intellectual capabilities through knowledge creation. Thus, in order to sustain competitive advantage, managers' understanding of knowledge creation and transfer is vital as the success of a company might be determined by managers' intellectual capital.

Although a variety of studies were conducted on the knowledge creation and transfer, most of them have focused on the source and state of knowledge (Alavi \& Leidner, 2001) and not much has been paid to explore conditions and organizational cultures that facilitate knowledge creation and transfer within organizations. There are various means by which an organization can facilitate and support the knowledge creation and transfer processes, however not much has been said on the role of learning organization as a valuable means of facilitating learning and knowledge management (Weldy, 2009). Learning organizations comprise of embedded systems to capture and share knowledge (Marsick \& Watkins, 2003; Watkins \& Marsick, 1993), so that they may continue to progress and develop competitively.

\section{What is Knowledge?}

Before discussing knowledge creation and transfer, understanding the concept of knowledge is vital as employees sometimes fail to obtain new knowledge due to their misunderstanding of the true concept. For a better understanding of the meaning of issues like data, information and knowledge need to be recognized. Generally, data are defined as raw facts, information is viewed as an organized set of data, and knowledge is conceived of as meaningful information (Bhatt, 2001). Based on Davenport \& Prusak (2000) knowledge is rooted in information and information is in turn 
originated from data. Argyris and Schon (1996, p. 3) argued that "While information is descriptive - that is, it relates to the past and the present - knowledge is eminently predictive, that is, it provides the basis for the prediction of the future with a degree of certainty based upon information”.

Although the word "knowledge" seems to be obvious and people use this word frequently, the definition of knowledge is not easy. It is due to different taxonomy of knowledge in organization. In order to understand the difficulty in defining knowledge, we must first distinguish the different kinds of knowledge. Knowledge has been categorized as hard and soft (Huber, 1991), formal and informal (Conklin, 1996), proprietary, public, personal, and commonsense (Boisot, 1995), tacit and explicit (Argote \& Ingram, 2000; Nonaka \& Takeuchi, 1995), embrained knowledge, embodied knowledge, embedded knowledge, and encoded knowledge (Blackler, 1995). There are various definitions of knowledge in the literature; however, the following definition seems to be more comprehensive than others: "Knowledge is the whole body of cognition and skill which individuals use to solve problems. It includes both theoretical and practical everyday rules and instructions for action. Knowledge is based on data and information, but unlike those two, it is always bound to persons. It is constructed by individuals, and represents their beliefs about causal relationships”(Probst, Raub, \& Romhardt, 2000, p. 24).

\subsection{Significance of knowledge and knowledge transfer}

Factors such as global economy, strategic unions, use of joint investment and access to markets around the world reveal that knowledge transfer is becoming increasingly significant in organizations (Eliufoo, 2005). In the knowledge based theory, knowledge and especially application of knowledge is the main factor of competitive advantage and organizational performance improvement (Alavi \& Leidner, 2001). According to Eliufoo (2005), knowledge is the main element by which firms can stand in a competitive position, and the means by which they can continuously expand their vision and reach the goals established by the firm. In addition, today's organizations show growing tendency to be more decentralized structures. In order to remain competitive, these organizations should manage their own needs. Therefore they have to capture, create and transfer new knowledge that they need.

\section{How Knowledge is Created and Transferred in Organizations?}

Some scholars (Allee, 1997; Nonaka \& Takeuchi, 1995; O'Dell, O'Dell, Grayson, \& Essaides, 1998; Sverlinger, 2000; Szulanski, 2000) have tried to simplify knowledge transfer and creation. However, Nonaka (1994) argued that knowledge can be created, shared, improved, and justified via collaborative, social processes and individual's cognitive processes such as reflection.

$<$ Table 1 about here $>$

Nonaka and Takeuchi (1995) hold that conversion between tacit and explicit knowledge results in knowledge. Accordingly, they developed four-mode model of knowledge creation and transfer as follows:

1. Socialization: In this process, tacit knowledge will be transferred through social contact (communications and interactions) such as discussions, sharing experience, simulation, practice, observation and so on among organizational members.

2. Externalization: In this process tacit knowledge is converted into explicit knowledge in the shapes of concepts, metaphors, hypothesis, descriptions and models. This process occurs when the firm formally articulates its internal rules of functioning or when it establishes its goals explicitly (Martín de Castro, 2007).

3. Combination: In this process explicit knowledge will be created from explicit knowledge. In this mode existing explicit knowledge is merged, categorized, reclassified, and synthesized to create new explicit knowledge (Alavi \& Leidner, 2001). Explicit knowledge can be transferred through media such as documents, meetings, storytelling and electronic communications (Yahoo Messenger, Skype, E-mail and/or phone conversations).

4. Internalization: internalization is achieved through changing explicit knowledge into tacit knowledge through a process in which abstract ideas change into concrete ones and they are finally absorbed as an integral value.

These four processes indicate that the knowledge transfer is effected when the knowledge user gains the same common knowledge of the concept as the knower.

$<$ Figure 1about here $>$

This model presents an analysis of knowledge creation processes through the epistemological dimension (Martín de Castro, 2007). Based on the assumption mentioned above, Nonaka et al (1995) suggested four modes of knowledge conversion: (1) from tacit knowledge to tacit knowledge, (2) from explicit knowledge to explicit knowledge, (3) from tacit knowledge to explicit knowledge, and (4) from explicit knowledge to tacit knowledge. 
According to Nonaka et al (1995) this cycle is formed through a number of conversions between different modes of knowledge. The shifts between the different modes by which knowledge is created can be on elicited by organizations. By building a team or field of interaction in socialization mode, members' experiences and perspectives can be shared with other organizational members within organization. In addition by providing meaningful dialogue and discussions in the externalization mode, employees can articulate their own perspectives.

\section{How Learning Organization Can Facilitate Knowledge Creation and Transfer?}

Organizations cannot survive and improve themselves with their previous knowledge and need to learn in order to strive hard to overcome the chaotic and changing conditions (Hannah \& Lester, 2009). According to Watkins and Marsick (1993), changes in organizations, the changing nature of work, changes in the workforce and changes in how people learn, are forces compelling organizations to shift to learning organizations. In order to keep in the organizational memory all the learning that takes place, it needs to be acquired by systems. Learning organizations always seek to find ways to capture the learned concepts in order to go on to function even if a highly mobile, temporary workforce fails to function well. Moreover, the organizations need to defuse all that is learned to even highly dispersed workforce, irrespective of how far they are located (Watkins \& Marsick, 1993). According to Senge (1990, p. 7) a learning organization is an organization "where people continuously expand their capacity to create the results they truly desire, where new and expansive patterns of thinking are nurtured, where collective aspiration is set free, and where people are continually learning how to learn together”.

The learning organization can be viewed as a system, i.e. seeing parts in relation to the whole, (Bui \& Baruch, 2010) that offers concepts serving to create an organizational culture which is capable of adapting itself to change and continually learning on multiple levels in order to promote their organization by creating their desired prospects (Senge, 1990; Watkins \& Marsick, 1993, 1996). A learning organization helps to facilitate the learning of all its members and consciously modifies itself and affects its context (Pedler, Burgoyne, \& Boydell, 1996). Additionally, learning organizations comprise embedded systems to capture and share knowledge so that the organization may continue to progress and develop competitively (Calantone, Cavusgil, \& Zhao, 2002; Gonzalez, 2010). Consequently, learning organizations facilitate knowledge creation and transfer within organization as follows:

\subsection{Facilitate Learning in Organizations}

A learning organization has democratic culture and embedded systems to capture and share learning based on problem solving cycle. In this particular organization, employees can always learn by changing their ordinary challenges into learning opportunities, seeking the experience as they think about action, assessing solutions, surveying results, and applying new ideas to deal with similar experiences in future (Watkins \& Marsick, 1993). Learning is a vital aspect of knowledge acquisition without which knowledge cannot be created. Therefore for knowledge creation, an organization needs to have a system to facilitate learning for its members. According to Watkins \& Marsick (1993), a learning organization facilitates learning to the whole organization at individual, team and organizational level. Shared vision and mental models (Senge, 1990; Watkins \& Marsick, 1993) as dimensions of learning organization are key factors to develop learning in organizations. A learning organization facilitates the learning of all its members and consciously modifies itself and affects its context (Pedler, et al., 1996) in order to develop embedded systems to capture and share knowledge so that the organization may continue to progress and develop competitively (Calantone, et al., 2002; Gonzalez, 2010).

\subsection{Convert tacit Knowledge to Explicit Knowledge}

If organizations want to access tacit knowledge and share it with members of organization, they must convert tacit knowledge to explicit knowledge. In order to gain and create knowledge within organizations, members need to transform tacit knowledge into explicit knowledge (Nonaka \& Takeuchi, 1995). A learning organization converts tacit knowledge to explicit knowledge trough discussion, dialogue and experiences shared in organization.

\subsection{Generate New Knowledge}

One of the important tasks for a learning organization is to create new knowledge in organization and acquire needed knowledge from outside. Learning organizations thrive on quality knowledge and communications. Therefore knowledge should be easily accessible whether received from people or through information technology (Marquardt, 2002). According to Garvin (1993, p. 80) “A learning organisation is an organisation skilled at creating, acquiring and transferring knowledge and at modifying its behaviour to reflect new knowledge and insights". In addition, "Learning organization presents new way of thinking about feedback, questioning, listening, talking, reflecting, and making sense of experience for individual to learn, but also for that learning to be shared with others in teams and used to make changes in the organizations” (Watkins \& Marsick, 1993, p. 43). According to Nonaka and Takeuchi (1995) knowledge 
is first created by individuals, after that through a process it is converted to organizational knowledge. As in a learning organization, people are proactive, reflective and creative in their learning and the process of learning is supported through different mechanisms (Marquardt, 2002; Marsick \& Watkins, 2003), it can be argued that new knowledge will be created easier in learning organizations.

\subsection{Double-loop Learning in Learning Organization}

Learning in learning organization is continuous and strategically tied to future organization needs. In addition a learning organization can generate flexible construction to increase learning for all employees (Watkins \& Marsick, 1993). Everyone in a learning organization is encouraged to seek information, ideas, and insights from other successful companies as well as from leading researchers (Marquardt, 2002). Furthermore, learning organizations link learning with business initiatives and organizational changes (Watkins \& Marsick, 1993) and also support processes and structures such as double-loop learning, deutero learning, therefore the creation, sharing and transfer of knowledge should be better organized, managed and achieved within a learning organisation.

\subsection{Manage Knowledge}

Organizations usually have good tacit and explicit knowledge; however in the absence of learning organization characteristics, it may be difficult for them to categorize and manage their existing knowledge. Embedded systems, leadership, employee suggestions, quality circles, and employee problem-solving groups and other learning organization traits help organizations to categorize and manage knowledge in order to increase organizational memory. According to Weldy (2009), there are vital factors for an organization to become a learning one and transfer training appropriately which are needed for learning enhancement, better management of knowledge, improvement of both individual and organizational performance so that the whole organization stands a chance to function actively even in uncertain markets.

\subsection{Create the Applicable Knowledge}

The processes of knowledge creation and transfer do not necessarily lead to improved organizational performance as organizational performance is often determined more by its ability to turn knowledge into effective action and less by knowledge itself (Alavi \& Leidner, 2001). "Learning companies create knowledge by reviewing their successes and failures, subjecting them to systematic assessment and transferring and recording what is learned in a way that will be of maximum benefit to the organization” (Marquardt, 2002, p. 151). In addition, in the learning organization, learning is highly social and people learn as they work together and in an interactive manner (Watkins \& Marsick, 1993). Everyone is encouraged to become adept at gathering data. All employees should be aware of the kind of knowledge that might benefit the organization so that they can capture it as it goes by (Marquardt, 2002). Therefore in learning organizations knowledge is transformed in applicable way in order to improve organizational performance.

\section{Knowledge Creation Requirements}

Mechanisms and strategies such as organizational structural styles, organizational strategies, communication, trust, motivations, learning and training can be considered as factors that influence creating and sharing knowledge culture. However, according to Takeuchi \& Nonaka (2004) the following factors are considered as conditions in fostering the knowledge creation spiral:

Intention: Intention deals with how individuals' attitude towards the world is formed and how they make sense of their environment. Every organization has its own vision, the objectives to be achieved in the long run, and the performance that is expected which specifies y its future position. Organizational intention, thus, is the outcome of sublime prospects and rigid criteria and standards.

Autonomy: Autonomy as a driver of motivation can encourage individuals and groups to create knowledge. The organization can manage to enhance the possibility of creating unexpected opportunities by providing people with opportunities to act independently. Autonomy gives individuals freedom to absorb knowledge.

Fluctuation and creative chaos: Allowing interaction within the organization and the external environment make feasible questioning of knowledge that is already created and can be enhanced. Individuals and organizations may become more creative when they are stimulated by some external factors that cause them to reconsider how they look at and how they interact with that world.

Redundancy: Redundancy can be considered as one of the knowledge creation conditions. There are some ways for building redundancy into organizations such as : introduction of overlapping approaches for example when different departments work together, having strategic rotation and frequent meetings both on regular and irregular bases, or facilitating formal and informal networks - such as after office get-togethers (Eliufoo, 2005). 
Required Variety: Refers to an organizational internal diversity that enables it to deal with the variety and complexity posed by the environment (Eliufoo, 2005). An organization that has greater diversity in its resources will be able to draw different perspectives or adopt a multifaceted approach in addressing issues and challenges.

\section{Role of managers to promote knowledge creation and transfer in a learning organization}

6.1 Designing suitable Construct: Knowledge cannot be created and converted easily. In order to facilitate knowledge creation and transfer, a manager should design a structure, in which organizational members can share their information and experience, improve and synthesize their knowledge, and also evaluate their ideas. A suitable structure can support problem solving, critical thinking and innovation that are very important for knowledge creation and transfer.

6.2 Training: To work as a group, to cope with their duty needs, to share their knowledge and experiences with others, and to create and transfer new knowledge, organizational members need to be trained. In addition, people need to know how they can identify the problems, how they can manage and solve the problems and how they can evaluate their works.

6.3 Motivation: Managers should create an organizational culture to encourage individuals and groups in order to share their ideas and knowledge. Organization members must adopt the assumption that collective ideas are better than those held in private. The organization can facilitate knowledge sharing and offer incentives for dialogues and team work.

6.4 Technology: One of the important factors that affect knowledge creation and transfer is communication. Without effective communication, organization members cannot share their ideas and knowledge and consequently knowledge creation and transfer will be complex. For this purpose managers can use technology such as the media and internet. For example e-learning, face book, email and video presentation are considered to be very helpful.

\section{Conclusion}

Contrary to individual knowledge creation, organizational knowledge creation occurs when all four modes of the creation of knowledge are "organizationally" managed to achieve a continual cycle (Nonaka, Byosiere, Borucki, \& Konno, 1994; Nonaka \& Takeuchi, 1995). Despite its being highly vital for organizations, it is quite difficult to convert tacit knowledge into explicit knowledge. Otherwise, they can fail to create new knowledge. Nonaka and Takeuchi's model (1995) demonstrates how knowledge can be created and transferred through the process of the tacit and explicit modes of knowledge. In Socialization mode, knowledge is created from tacit knowledge to new tacit knowledge; in externalization mode tacit knowledge is changed into explicit knowledge; in the combination mode an explicit form of knowledge develops into another new explicit form; and finally in the internalization mode explicit knowledge is converted into tacit knowledge. A learning organization enables individuals and team members to express their own ideas and perspectives. Collective exploration of ideas improves organizational memory especially when the organization embeds the knowledge in its system. The learning organization can serve as one major factor that can contribute to the sharing of experiences and perspectives among the members so that tacit knowledge is converted into explicit knowledge. This can be achieved through such processes of organizational learning as facilitating learning in organizations, generating new knowledge, double-loop learning and creating the applicable knowledge and the functions of the manager in the organization like designing suitable construct training, motivating the people in the organization, enhancing communication among the members and utilizing new and efficient technology in workplace.

\section{References}

Alavi, M., \& Leidner, D. E. (2001). Review: Knowledge management and knowledge management systems: Conceptual foundations and research issues. MIS quarterly, 107-136. doi:10.2307/3250961, http://dx.doi.org/10.2307/3250961

Allee, V. (1997). The knowledge evolution: Expanding organizational intelligence: Butterworth-Heinemann.

Argote, L., \& Ingram, P. (2000). Knowledge Transfer: A Basis for Competitive Advantage in Firms* 1. Organizational behavior and human decision processes, 82(1), 150-169. doi:10.1006/obhd.2000.2893, http://dx.doi.org/10.1006/obhd.2000.2893

Argyris, C. Y. S., \& Schön, D. (1996). Organizational learning II: Theory, method and practice. Reading, PA: Addison-Wesley.

Bhatt, G. D. (2001). Knowledge management in organizations: examining the interaction between technologies, techniques, and people. Journal of Knowledge Management, 5(1), 68-75. doi: 10.1108/13673270110384419, http://dx.doi.org/10.1108/13673270110384419 
Blackler, F. (1995). Knowledge, knowledge work and organizations: an overview and interpretation. Organization studies, 16(6), 1021. doi:10.1177/017084069501600605, http://dx.doi.org/10.1177/017084069501600605

Boisot, M. (1995). Information space: A framework for learning in organizations, institutions and culture: Thomson Learning Emea.

Bui, H., \& Baruch, Y. (2010). Creating learning organizations: a systems perspective. The Learning Organization, 17(3), 208-227. doi: 10.1108/09696471011034919, http://dx.doi.org/10.1108/09696471011034919

Calantone, R., Cavusgil, S., \& Zhao, Y. (2002). Learning orientation, firm innovation capability, and firm performance. Industrial Marketing Management, 31(6), 515-524. doi:10.1016/S0019-8501(01)00203-6, http://dx.doi.org/10.1016/S0019-8501(01)00203-6

Conklin, J. (1996). Designing organizational memory: preserving intellectual assets in a knowledge economy. Group Decision Support Systems, 1, 362.

Davenport, T. H., \& Prusak, L. (2000). Working knowledge: How organizations manage what they know: Harvard Business Press.

Eliufoo, H. K. (2005). Knowledge creation and transfer in construction organisations in Tanzania: Building and Real Estate Economics, Royal Institute of Technology.

Gonzalez, A. M. (2010). The U.S. Army: A Learning Organization. SSRN eLibrary.

Gray, J. H., \& Densten, I. L. (2005). Towards an integrative model of organizational culture and knowledge management. International Journal of Organisational Behaviour, 9(2), 594-603.

Hannah, S., \& Lester, P. (2009). A multilevel approach to building and leading learning organizations. The Leadership Quarterly, 20(1), 34-48. doi:10.1016/j.leaqua.2008.11.003, http://dx.doi.org/10.1016/j.leaqua.2008.11.003

Huber, G. (1991). Organizational learning: The contributing processes and the literatures. Organization science, 2(1), 88-115. doi:10.1287/orsc.2.1.88, http://dx.doi.org/10.1287/orsc.2.1.88

Ichij , K., \& Nonaka, I. (2007). Knowledge creation and management: new challenges for managers: Oxford University Press, USA.

Marquardt, M. J. (2002). Building the learning organization : mastering the 5 elements for corporate learning (2nd ed.). Palo Alto, CA: Davies-Black Pub.

Marsick, V., \& Watkins, K. (2003). Demonstrating the value of an organization's learning culture: the dimensions of the learning organization questionnaire. Advances in Developing Human Resources, 5(2), 132. doi:10.1177/1523422303005002002, http://dx.doi.org/10.1177/1523422303005002002

Martín de Castro, G. (2007). Knowledge creation processes : theory and empirical evidence from knowledge-intensive firms. Basingstoke England ; New York: Palgrave Macmillan.

Nonaka, I. (1994). A dynamic theory of organizational knowledge creation. Organization science, 5(1), 14-37.

Nonaka, I., Byosiere, P., Borucki, C. C., \& Konno, N. (1994). Organizational knowledge creation theory: a first comprehensive test. International Business Review, 3(4), 337-351. doi:10.1287/orsc.5.1.14, http://dx.doi.org/10.1287/orsc.5.1.14

Nonaka, I., \& Takeuchi, H. (1995). The knowledge-creating company: how Japanese companies create the dynamics of innovation. 1995. doi:10.1016/0969-5931(94)90027-2, http://dx.doi.org/10.1016/0969-5931(94)90027-2

O'Dell, C. S., O'Dell, C., Grayson, C. J., \& Essaides, N. (1998). If only we knew what we know: The transfer of internal knowledge and best practice: Free Pr.

Pedler, M., Burgoyne, J., \& Boydell, T. (1996). The learning company: a strategy for sustainable development; The learning company: a strategy for sustainable development: McGraw-Hill.

Probst, G., Raub, S., \& Romhardt, K. (2000). Managing knowledge: Building blocks for success (Vol. 360): John Wiley \& Sons.

Senge, P. (1990). The Fifth Discipline. The Art and Practice of the Learning Organization. New York: Currency Doubleday.

Sverlinger, P. (2000). Managing knowledge in professional service organisations. Technical Consultants Serving the Construction Industry, Chalmers Reproservice, Gothenburg, Sweden. 
Szulanski, G. (2000). The Process of Knowledge Transfer: A Diachronic Analysis of Stickiness* 1. Organizational behavior and human decision processes, 82(1), 9-27. doi:10.1006/obhd.2000.2884, http://dx.doi.org/10.1006/obhd.2000.2884

Takeuchi, H., \& Nonaka, I. o. (2004). Hitotsubashi on knowledge management. Singapore: John Wiley \& Sons (Asia).

Watkins, K., \& Marsick, V. (1993). Sculpting the learning organization: Jossey-Bass San Francisco.

Weldy, T. (2009). Learning organization and transfer: strategies for improving performance. The Learning Organization, 16(1), 58-68. doi: 10.1108/09696470910927678, http://dx.doi.org/10.1108/09696470910927678

Zollo, M., \& Winter, S. G. (2002). Deliberate learning and the evolution of dynamic capabilities. Organization science, 339-351. doi:10.1287/orsc.13.3.339.2780, http://dx.doi.org/10.1287/orsc.13.3.339.2780

Table1: Stages of a knowledge transfer process

\begin{tabular}{|c|c|}
\hline Author/s & Process \\
\hline Nonaka and Takeuchi (1995) & 1. Socialization 2. Externalization 3. Combination 4. Internalization \\
\hline Allee (1997) & 1. Collect 2. Identify 3. Create 4. Share 5. Apply 6. Organize 7. Adapt \\
\hline O'Dell, et al.(1998) & 1. Create 2. Identify 3. Collect 4. Organize 5. Share 6. Adapt 7. Use \\
\hline Szulanski (2000) & 1. Initiation 2. Implementation 3. Ramp-up 4. Integration \\
\hline Sverlinger (2000) & $\begin{array}{l}\text { 1. Knowledge acquisition 2. Information distribution 3. Making meaning } 4 . \\
\text { Organizational memory 5. Retrieval of knowledge }\end{array}$ \\
\hline Zollo and Winter (2002) & 1. Variation 2. Selection 3. Replication 4. Retention \\
\hline
\end{tabular}

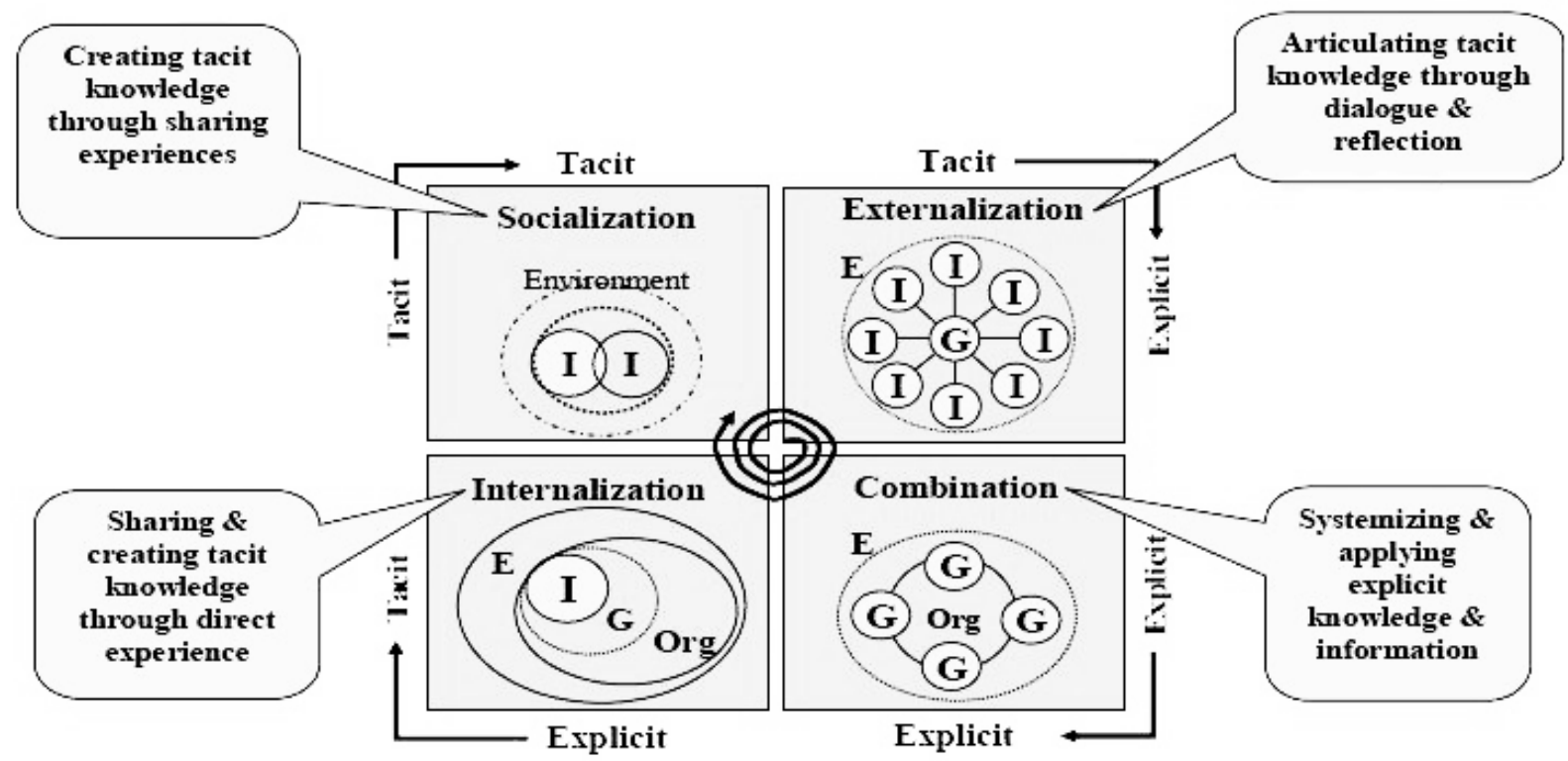

I= Individual; G= Group; O= Organization; E= Environment

Figure 1: An adapted Model of Nonaka \& Toyama’s Knowledge Creation (Gray \& Densten, 2005, p. 597) 